\title{
ESTATUETAS DE ARTE NATURAL (ALRUNAS) DIGNAS DE FIGURAR NUM MUSEU DE ARTE MODERNA.
}

Chamamos "Arte Natural" a estatuetas com forma humana feitas de raízes, tocos e galhos de vegetais, que se encoiltram na natureza já esboçadas e quase pré-figuradas.

As estatuetas de Arte Natural só em parte foram produzidos pela natureza, pois ela fornece apenas a matéria o motivo. A maior parte é do Artista humano que deve retocar o que a natureza produziu.

Muitas vêzes nessa matéria bruta, o artista enxerga com olhar infalível uma figura grotesca. Começa entãn a revelar (como uma chapa fotográfica) mediante seus instrumentos de entalhação, como sejam o buril e o estilete, uma figura variável, de acôrdo com os membros e a posição que o rìaterial sugere. O artista dotado de imaginação e tino pode comunicar, desta forma, à matéria inerte uma nova existência de uma figura humana ou animal. Em geral, só é necessário cinzelar a cabeça e um ligeiro retoque no tronco, pernas e mãos, mas os pés ficam atrofiados devido à natureza das raízes que terminam em ponta.

Na mão de um artista hábil a natureza quase que começa a falar, quando tira da vida potencial um calunga com sua fisionomia particular.

A Arte Natural pode aproveitar e transformar tanto tocos, ramos e galhos, como raízes que servem para o fim almejado. Todavia, nós escolhemos tão sòmente estatuetas antropomorfas feitas de raízes.

Estas estatuetas são chamadas também "alrunss". O material usado para tal fim era originàriamente a raiz da Mandragora, a qual é lenhosa e quase sempre se divide em duas, a ponto de sugerir uma vaga forma humana. Foi essa forma da raiz (comum nesta planta) que deu origem às alrunas. Mas foram e ainda são usadas para êsse fim raízes de cutras plantas, como as da Bryonia, Allium e Panax e muitas outras plan- 
tas que apresentam a raiz bipartida. Servem desta forma as: raízes de muitas plantas', como indicaremos mais adiante, nos. casos que foi possivel descobrir.

A estatuetas antropomorfas que exibimos foram criadas: por vários artistas e se acham no Museu Florestal iju alhures.

O artista mais célebre neste ramo de arte é W. Lehmann, da Suiça, sôbre cuja obra Robert Lejeune publicou um livro.

Êste artista aproveita não sòmente raízes, mas também colo e caule, criando figuras bem interessantes, das quais reproduzimos algumas que foram feitas de raízes.

No Brasil, conhecem-se desde 1936 essas figuras antropc-morfas. Foi iniciado êsse trabalho pelo ucraniano $M$ Korchowski para o Museu Florestal de São Paulo. Entre os vários objetos de Arte Natural, para os quais aproveitou tocos e toras, escolhemos também sòmente os objetos antropomorfos feitos de raízes.

Uma dessas figuras se deve ao entalhador A. Oppido que, com mão feliz e entendimento perfeito, criou a estatueta deum aleijado sem braços e com uma só perna.

Ültimamente surgiu, entre nós, mais um dêsses artistas que sabem dar vida a objetos inertes e toscos e criai uma arte que foi muito admirada na exposição realizada na Galeria. Prestes Maia. O artista é o Sr. 'José Vaz Pupo Nogueira. A matéria prima todavia era tirada de galhos de árvores e não. de raízes. Por êste motivo não incluímos nenhim dos seus trabalhos, porque nosso objetivo se limita às figuras oriundasi de raízes.

O documentário dêste trabalho consta de 17 figuras dês-. ses três artistas. Lehmann, espírito observador, dotado de uma rica imaginação, aliada ao amor e familiaridade com a natureza, chegou a criar numerosas figuras que, ocultas no seio da natureza, tomaram forma e vida, sob as suas mãos habilíssimas.

Há entre elas duendes, trasgos, diabretes, gnomos e failnos, algumas com fisionomia risonha e outros carrancudus, com ares de escárneo e ironia, prontos para as suás travessuras e diabruras. Suas risadas sarcásticas são dirigidas contra os homens que diante dêles desfilam apressadis ou se arrastam acabrunhados no seu pessimismo. Essas risadas às vê- 
zes se transformam em zombaria quando escarnecem de tais homens nas suas extravagâncias grotescas, imitando. por exemplo, a sua marcha com fisionomia grave e pose severa (figs. 1 a 4 ).

Às vêzes a travessura dêsses duendes se exprime em danças, lançando a perna a tal altura que forma quase dois ângulos retos (fig. 5). Um outro, com seus volteios arriscados graciosamente executados, lembra uma daquelas figurinhas venezianas de vidro (fig. 6), e uma dançarina, com seus giros ritmados rodopia tão depressa que tronco e pernas formam como que um pião em torvelinho (fig. 7).

A fig. 8 representa um Mefisto que está empenhando-se em aferrar o homem à matéria, tentando enganá-lo àcêrca do real sentido da vida.

A fig. 9 lembra Sócrates, o filósofo grego, que procurou conduzir os homens ao conhecimento de si mesmos, com seu ensino sábio, um tanto irônico.

A fig. 10 é a corporificação de um vagabundo, cuja fisionomia, um misto de cinismo e timidez, corresponde bem a sua atitude de bajulação.

Um sábio (fig. 11) com gestos de professor, faz suas exortações aos homens, advertindo-os para evitar o mau caminho. Sua fisionomia evidencia ciência profunda àcêrca do destino do homem e suas feições ascéticas lhe dão o devido vigor. Sua mão é mutilada, mas eleva os três dedos que the ficaram para esconjurar seus ouvintes.

A fig. 12 mostra um semeador que espalha em largo gesto seus grãos, tendo prêso ao colo o saco; é um símbolo de um mundo melhor e mais belo, na esperança de que suas sementes germinem e as plantas cresçam e frutifiquem .

A fig. 13, uma figura de mulher, lembra uma sílfide ou fada que ostenta grande beleza, símbolo do bem e da pureza.

Os artistas do Miuseu Florestal que não ficani atrás de Lehmann, criaram as seguintes estatuetas:

Uma raiz de pinheiro do Paraná sugeriu ao $\mathbf{S}$. Antônio Oppido a idéia de representar um lenhador que no äã do seu trabalho na derrubada teve a infelicidade de perder uma perna, um braço e uma mão ficando completamente aleijado. A fisionomia, entretanto, é de um estóico, pois partec que não se sente tão infeliz como de fato é, dependente que fica dos outros em tudo, como comer, vestir, locomover-se (fig. 14). 


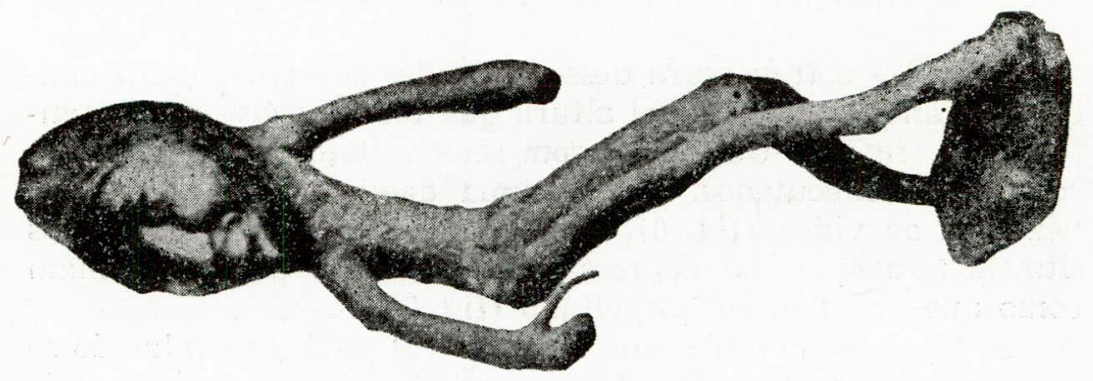

ai

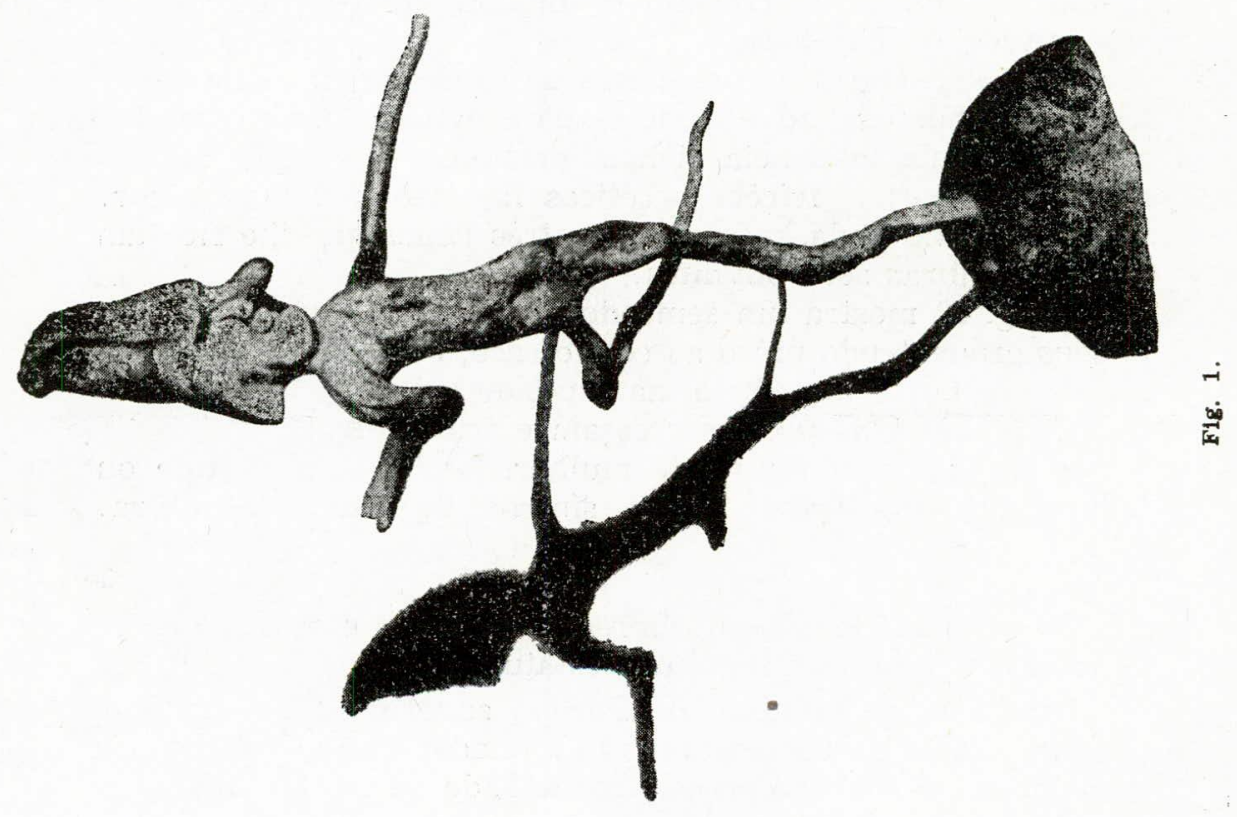




$$
\overrightarrow{q u}
$$


$-438-$
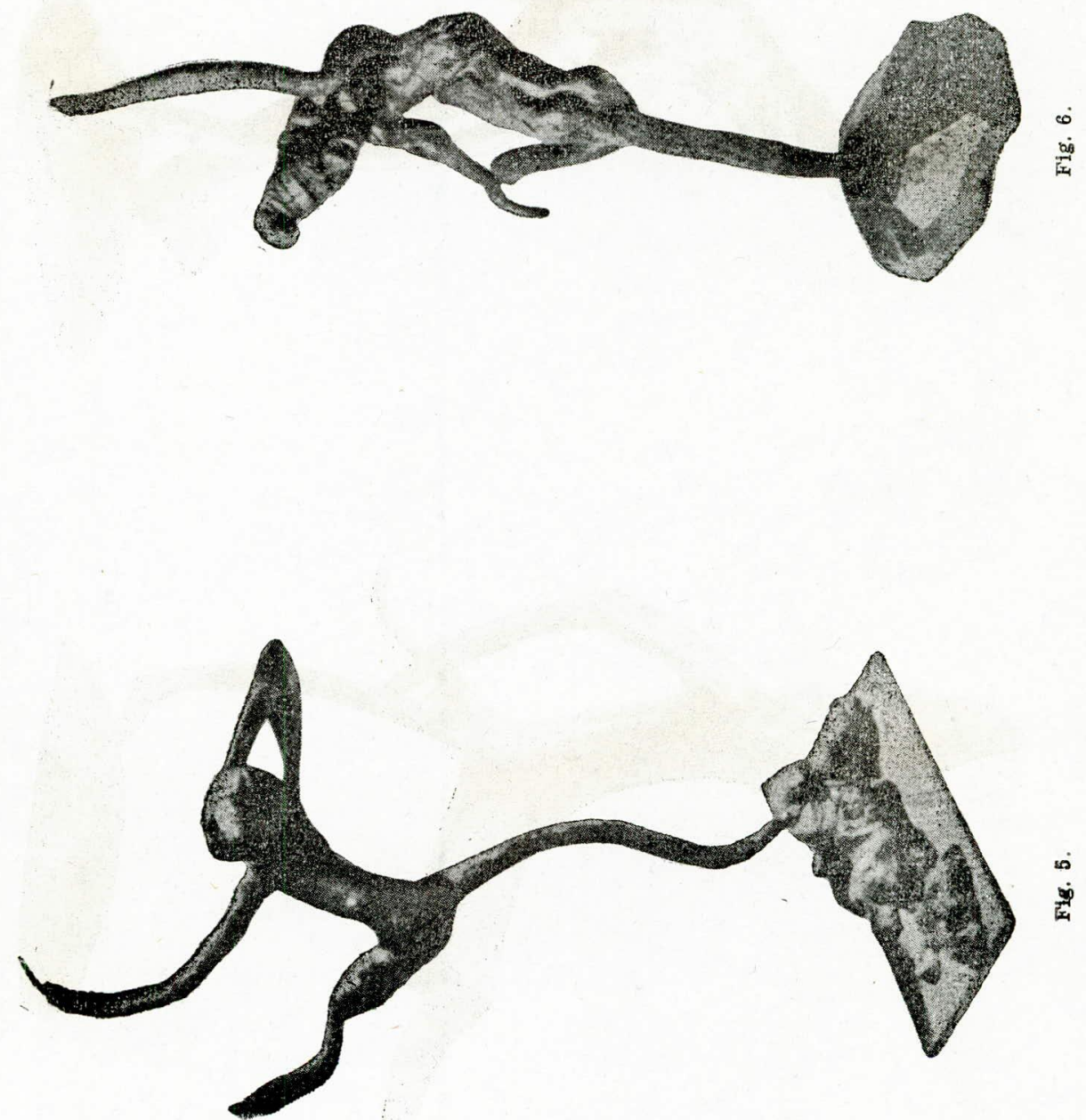

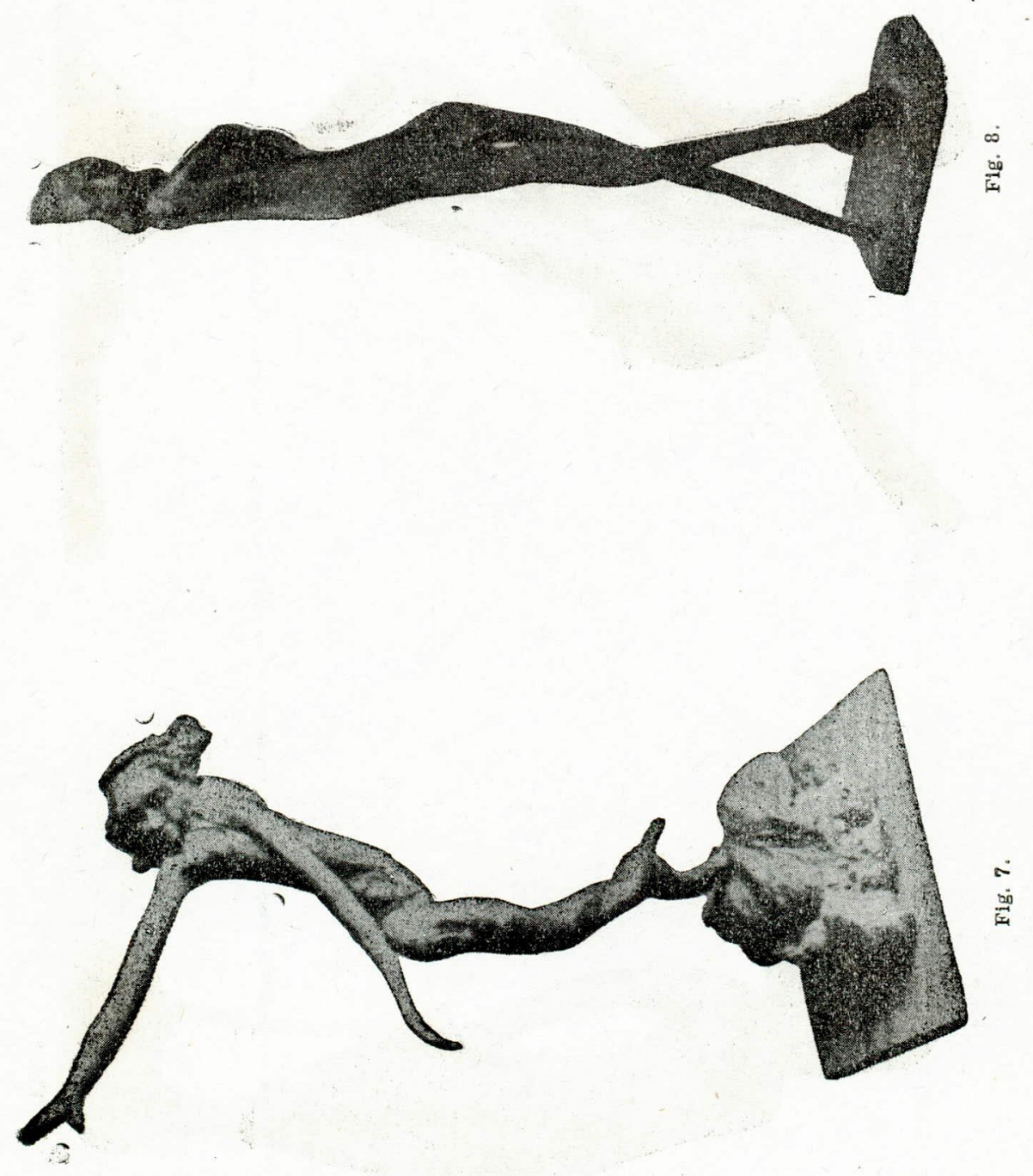

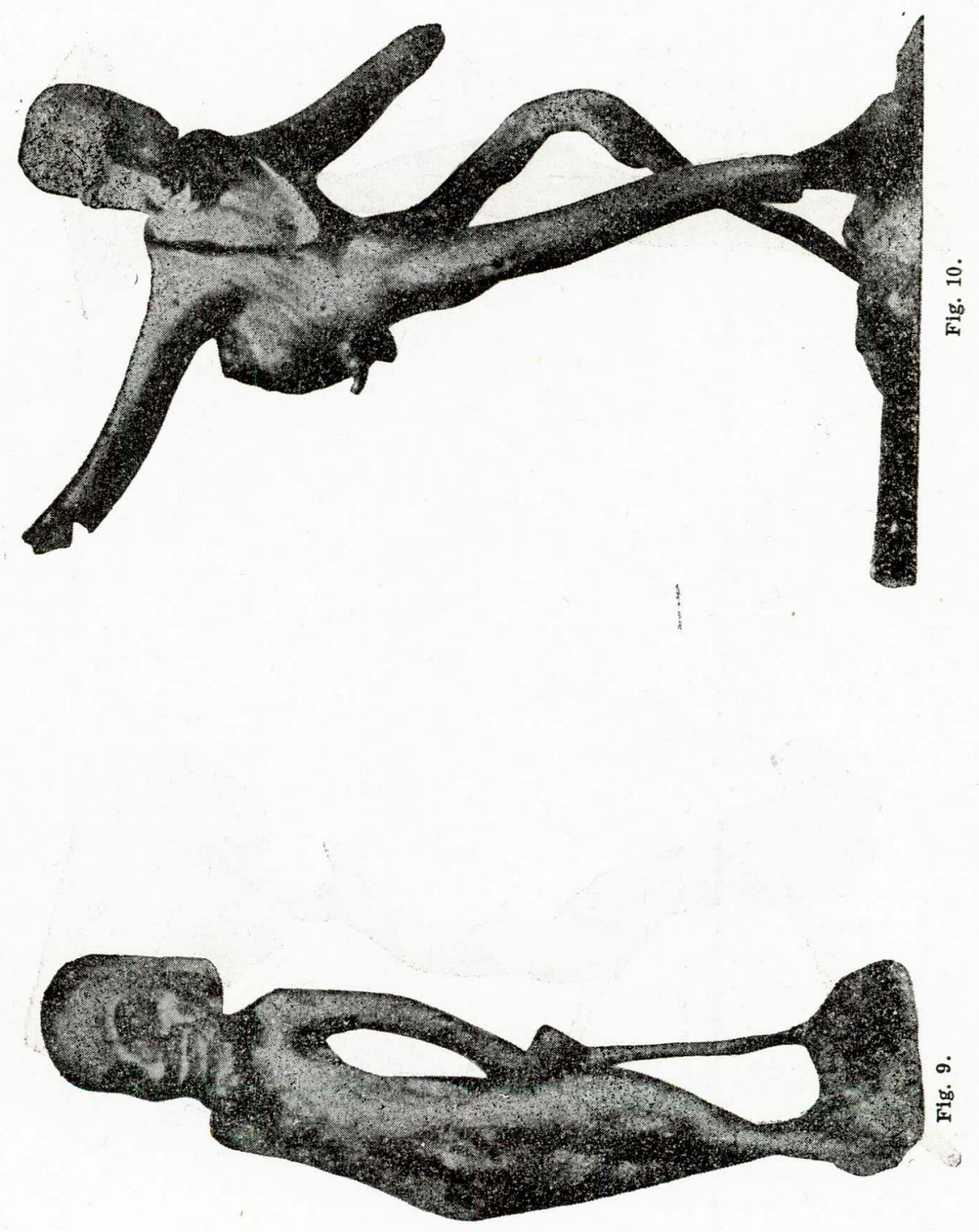

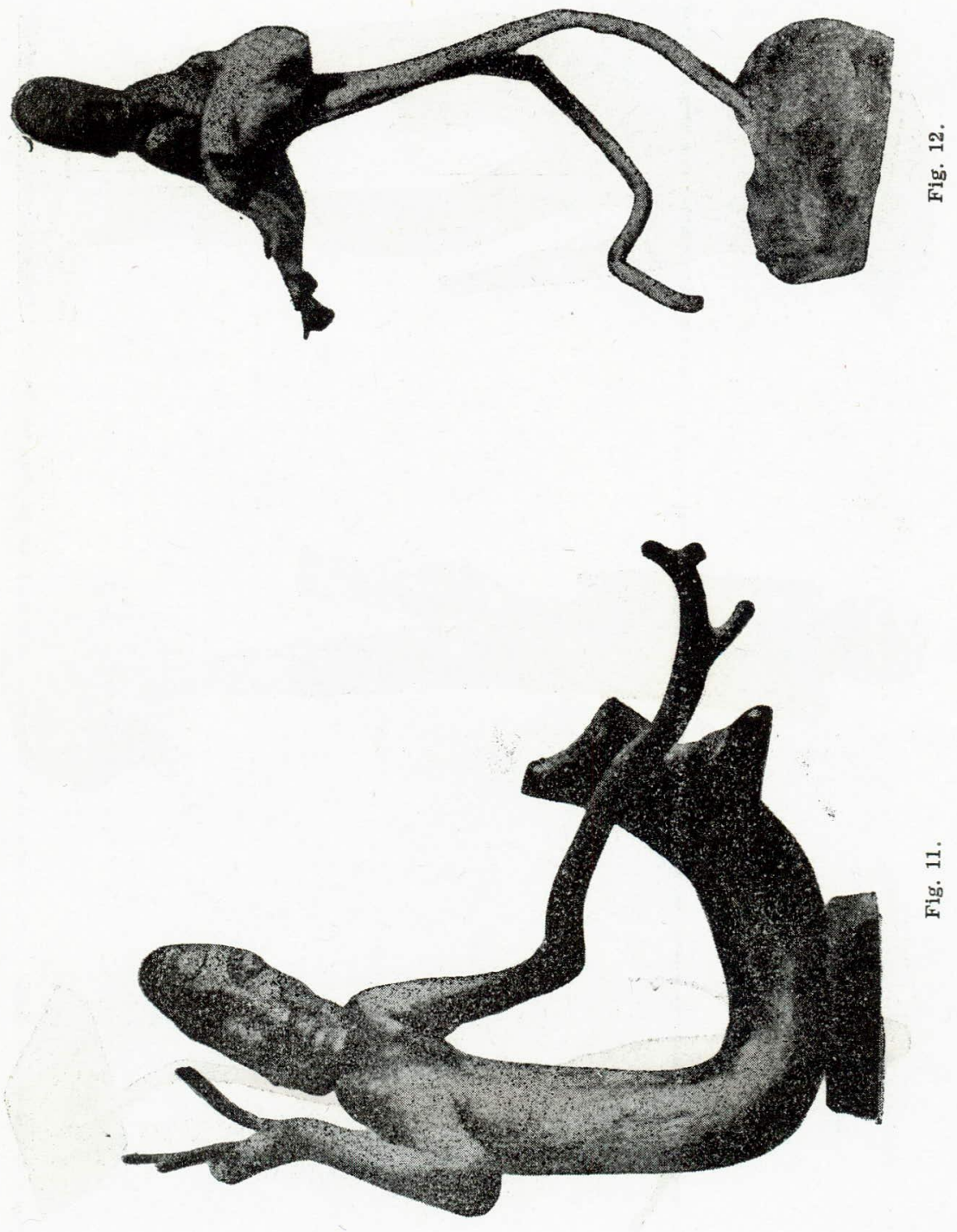


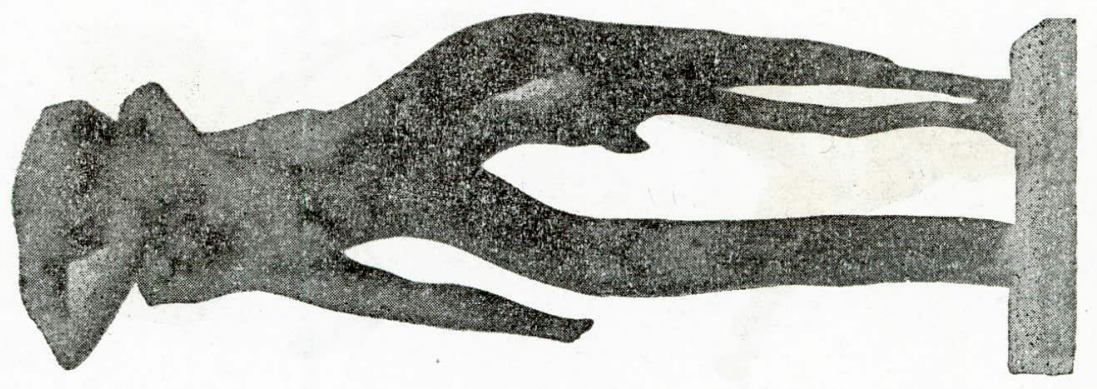

is

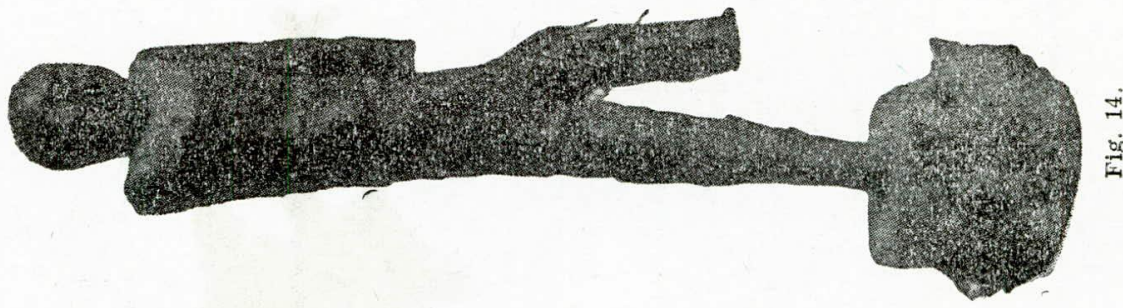

$\underset{i}{+}$

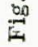

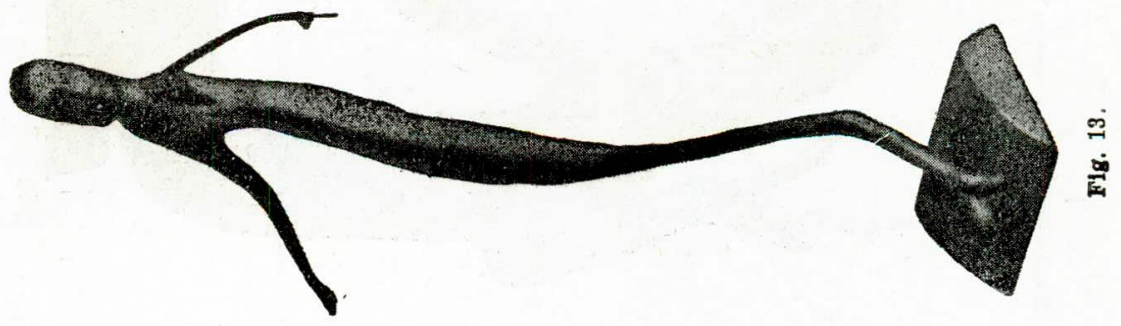



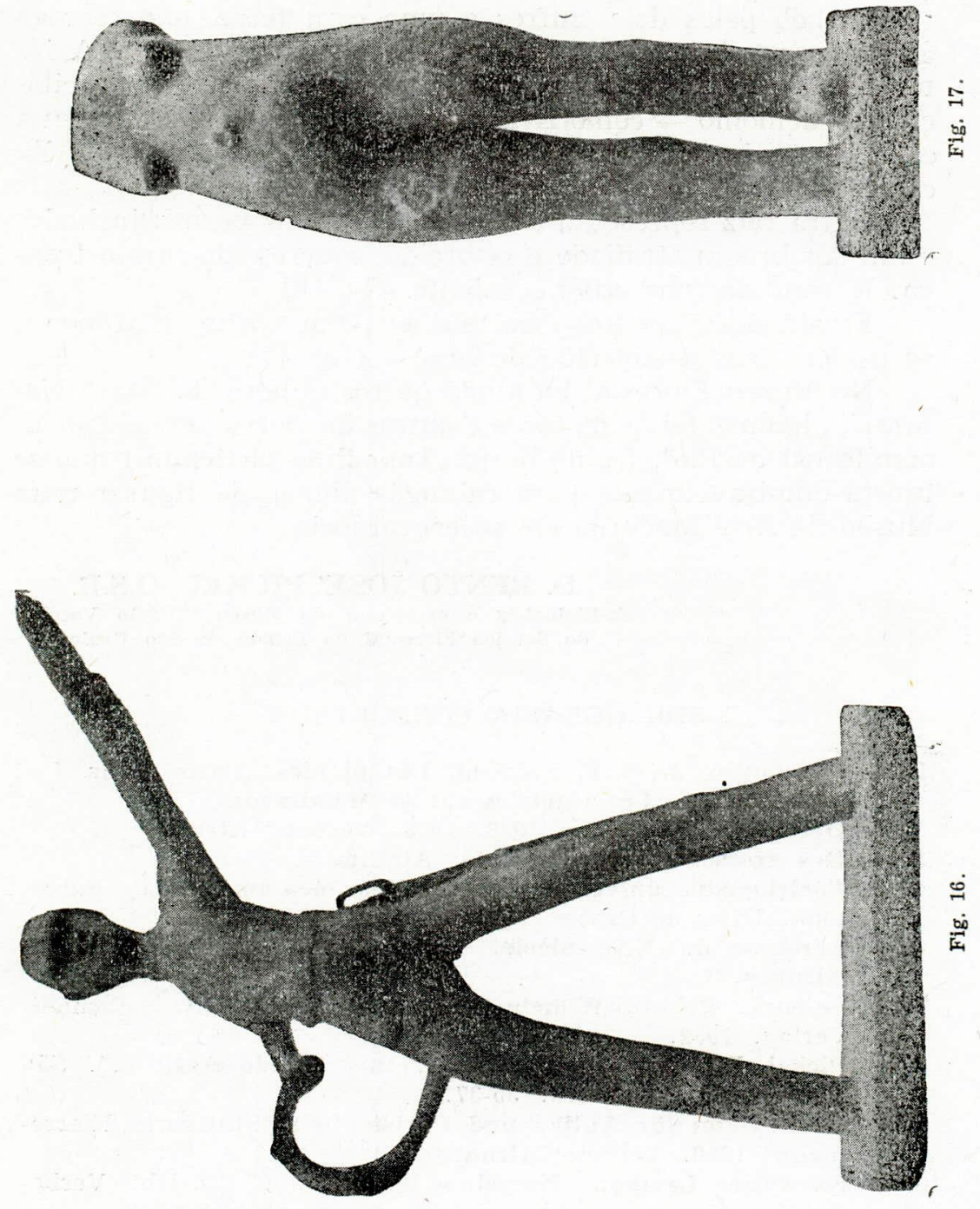
De uma raiz de laranjeira, que era um aglomerado de raízes menores, o sr. Korchowski fêz uma peça dupla, interessante, individualizando duas pessoas, a saber, o dfmônio, caracterizado pelos dois chifres e uma cara feroz. que carrega às costas uma mulher ou, antes, um torso de mulher. A interpretação dêste grupo é que a mulher cedendo às solicitações do demônio - como Eva no paraíso quando esta perdeu a cabeça - caiu nas garras do negregado Satanás e foi por êle carregada (fig. 15).

Outra raiz representa um soldado com as pernes inchadas e um dos braços atrofiado e retorcido, concrescido com o tronco. E' contudo combativo e valente (fig. 16).

Finalmente, um torso de mulher, com apenas o tronco e as pernas, mas desprovido de braços (fig. 17).

No Museu Florestal há ainda outros objetos de "Arte Natural", algumas feitas de tocos e outras de raízes aéreas (pneumatóforos) do Pinheiro do brejo (Taxodium distichum) que se presta admiràvelmente para calungas dignas de figurar num Museu de Arte Moderna em secção própria.

D. BENTO JOSE' PICKEL, O.S.B.

Ex-Biologista e ex-Diretor do Museu "Otávio Vecch1" do Serviço Florestal do Estado de Sáo Paulo.

\section{BIBLIOGRAFIA CONSULTADA.}

1. - Constantin, J. et F. Faideau, Les plantes. Paris. Libr. Larousse. 1922. Les légendes sur la Mandragora.

2. - Der grosse Brockhaus 1928. 1953. Verbete: Alrun.

3. - Des grosse Herder. Verbete: Alraun.

4. - Enciclopédia universal ilustrada europeu-americana. Barcelona. Hijos de Espasa, Edit. Verbete: Alrunes.

6. - Larousse du XXe Siècle. Paris. Libr. Larousse. Verbete: Alrunes.

7. - Lejeune, Robert, Wilhelm Lehmann. St. Gallen. TschudiVerlag. 1952 .

8. - Pickel, D. Bento José, Alrunas. In: "Mundo Agricola". São Paulo. 1957. Outubro. 35-37.

9. - Reallexikon für Antike und Christentum. Stuttgart. Hiersemann. 1950. Verbete: Alrun.

10. - Schweizer Lexikon. Encyclios Verlag A. G. Zurich. Verbete: Der Alraun.

11. - Starck, A. T. Handwörterbuch des dt. Aberglaubens. Baltimore. 1917. 